\title{
Metal oxide mesocrystals with tailored structures and properties for energy conversion and storage applications
}

\author{
Takashi Tachikawa ${ }^{1,2}$ and Tetsuro Majima ${ }^{1}$
}

Mesocrystals (MCs) are superstructures with a crystallographically ordered alignment of nanoparticles. Owing to their organized structures, MCs posses some unique characteristics such as a high surface area, pore accessibility, and good electronic conductivity and thermal stability; thus, MCs could be beneficial for many areas of research and application. This review begins with a description of the common synthesis strategies for, and characterization and fundamental properties of metal oxide MCs. Newly developed analytical methods (that is, photoconductive atomic force microscopy and single-molecule, single-particle fluorescence microscopy) for unraveling the charge transport and photocatalytic properties of individual MCs are then introduced. Further, recent developments in the applications of various metal oxide MCs, especially in the fields of energy conversion and storage, are also reviewed. Finally, several perspectives in terms of future research on MCs are highlighted. NPG Asia Materials (2014) 6, e100; doi:10.1038/am.2014.21; published online 16 May 2014

Keywords: energy storage; mesocrystal; metal oxide; photocatalysis; solar energy conversion; superstructure

\section{INTRODUCTION}

The self-assembly of nanoparticle building blocks into highly ordered superstructures is one of the actively pursued research topics in materials science and technology. ${ }^{1-4}$ Such hierarchical architectures have potentially tunable electronic, optical and magnetic properties, which promise various applications ranging from catalysis to optoelectronics. A mesocrystal (MC), which was first introduced by Cölfen in the early years of 2000s, is defined as a superstructure consisting of nanoparticles on the scale of several hundred nanometers to micrometers. ${ }^{5-11}$ In contrast to the classical mechanism of atom/ ion-mediated growth of a single crystal, the particle-mediated growth mechanisms of MCs are termed as non-classical crystallization (Figure 1). This definition has been developed in recent years, where MCs are defined entirely according to their structures rather than their formation mechanism. ${ }^{12}$ In this decade, a variety of MCs of metal oxides (for example, $\mathrm{TiO}_{2},{ }^{13-23} \mathrm{ZnO},{ }^{24-34}$ hematite $\left(\alpha-\mathrm{Fe}_{2} \mathrm{O}_{3}\right),{ }^{35-40}$ maghemite $\left.\left(\gamma-\mathrm{Fe}_{2} \mathrm{O}_{3}\right),{ }^{41} \quad \mathrm{Co}_{3} \mathrm{O}_{4},{ }^{42} \quad \mathrm{SnO},{ }^{43-45} \quad \mathrm{Ag}_{2} \mathrm{O},{ }^{46} \mathrm{CuO}^{47-49}\right)$, metal chalcogenides (for example, $\mathrm{ZnS},{ }^{50,51} \mathrm{PbS},{ }^{52} \mathrm{PbSe}^{53,54}$ ), metals (for example, $\mathrm{Au},{ }^{55} \mathrm{Ag},{ }^{56,57} \mathrm{Cu},{ }^{58} \mathrm{Pt},{ }^{59,60} \mathrm{Pd}^{61}$ ), organic compounds (for example, DL-alanine, ${ }^{62,63}$ DL-lysine $\cdot \mathrm{HCl}^{64}$ perylene derivatives ${ }^{65}$ ) and biominerals (for example, sea urchin spines, corals, egg shells) ${ }^{66}$ have been synthesized or discovered in nature.

Among metal oxides, $\mathrm{TiO}_{2}$ is used in many applications that deal with environmental and energy problems (for example, photodegradation of pollutants, ${ }^{67}$ water splitting for $\mathrm{H}_{2}$ evolution, ${ }^{68}$ dyesensitized solar cells ${ }^{68}$ and lithium-ion batteries ${ }^{69}$ ) owing to its chemical stability as well as its low cost and non-toxicity. When $\mathrm{TiO}_{2}$ is illuminated with ultraviolet (UV) light, electron-hole pairs are created simultaneously. Only a small part of the photogenerated charge carriers spatially separate via diffusion and facilitate surface reactions to generate reactive species (for example, $\mathrm{O}_{2}{ }^{\bullet-}$ and ${ }^{\bullet} \mathrm{OH}$ ) for subsequent oxidation/reduction processes on $\mathrm{TiO}_{2}$ surfaces. ${ }^{70}$ Thus, highly active photocatalysts require high charge separation efficiency in addition to a high specific surface area for the adsorption of reagents. Controlled crystal growth also determines the exposed facets of crystals as well as their shape and size, which have different surface physicochemical properties. ${ }^{71,72}$ As Yang et al. ${ }^{73}$ successfully synthesized anatase $\mathrm{TiO}_{2}$ single crystals with highly exposed reactive $\{001\}$ facets, enormous efforts have been devoted to the synthesis of anatase $\mathrm{TiO}_{2}$ crystals with different crystal planes exposed for better performance. ${ }^{74}$ Furthermore, mesoporous $\mathrm{TiO}_{2}$ single crystals with well-defined facets have been prepared and utilized in dye-sensitized solar cells and photocatalysis for $\mathrm{H}_{2}$ evolution and degradation of dyes. ${ }^{75,76}$

It has been suggested that the dense packing of $\mathrm{TiO}_{2}$ nanocrystals (NCs) enhances the photocatalytic activity and performance of dyesensitized solar cells owing to the efficient interparticle electron transfer between NCs. ${ }^{77-83}$ For example, the Choi group reported that mesoporous $\mathrm{TiO}_{2}$ consisting of compactly packed nanoparticles showed higher photocatalytic activity for $\mathrm{H}_{2}$ evolution than that shown by colloidal and commercial $\mathrm{TiO}_{2}$ samples in both UV and visible light (dye-sensitized) systems. ${ }^{78}$ In addition, transient

${ }^{1}$ The Institute of Scientific and Industrial Research (SANKEN), Osaka University, Osaka, Japan and 2PRESTO, Japan Science and Technology Agency (JST), Saitama, Japan Correspondence: Professor T Majima, The Institute of Scientific and Industrial Research (SANKEN), Osaka University, Mihogaoka 8-1, Ibaraki, Osaka 567-0047, Japan. E-mail: tachi45@sanken.osaka-u.ac.jp or majima@sanken.osaka-u.ac.jp

Received 1 December 2013; revised 14 January 2014; accepted 4 February 2014 
photocurrent measurements and random walk numerical simulations have shown that the ordering of a nanocrystalline structure significantly influences charge transport and recombination, which

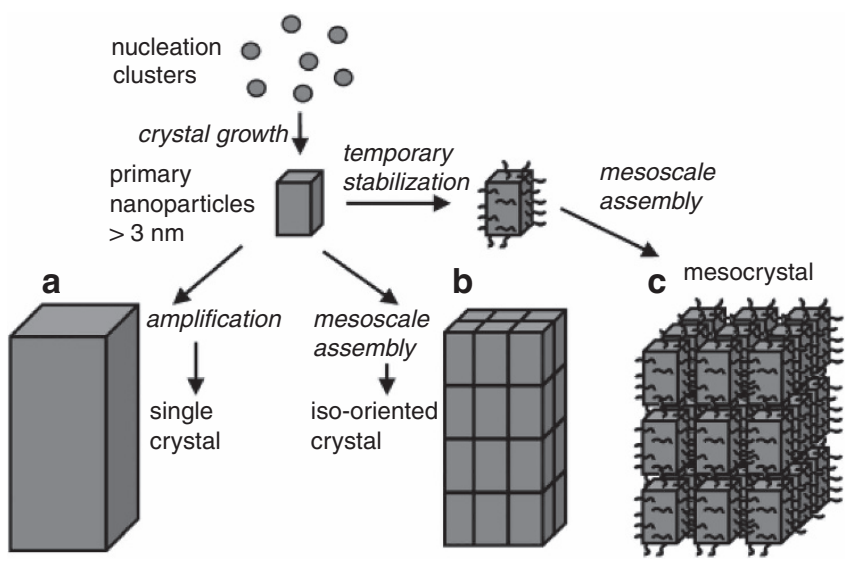

Figure 1 Schematic illustration of classical and non-classical crystallization. (a) Classical crystallization pathway, (b) oriented attachment of primary nanoparticles forming an iso-oriented crystal upon fusing, (c) mesocrystal (MC) formation via self-assembly of primary nanoparticles covered with organics. Reprinted with permission from reference Wohlrab et al.62 Copyright 2005 WILEY-VCH Verlag GmbH \& Co. KGaA, Weinheim. are closely related to the performance of photovoltaic cells. ${ }^{82,83}$ Zaban and co-workers ${ }^{82}$ found that the highest degree of ordering in porous $\mathrm{TiO}_{2}$ nanocrystalline films correlates with the highest values of effective diffusion coefficient. Indeed, MCs consisting of NCs highly oriented in the same direction are an ideal system to study this issue.

In this review, we focus on the synthesis and structures of metal oxide MCs, mostly $\mathrm{TiO}_{2} \mathrm{MCs}$, and their applications for energy conversion and storage. We selected examples, which showed the most marked enhancement of physical properties in applications. For instance, owing to their high specific surface area and mesoporous structures, $\mathrm{TiO}_{2}$ MCs could show higher photocatalytic activity for $\mathrm{H}_{2}$ evolution and organics degradation than that shown by bulk single crystals. The higher photocatalytic activity of $\mathrm{TiO}_{2} \mathrm{MCs}$ is strongly related to the facile interparticle electron transport between NCs in the MC superstructure. Finally, we summarize our contribution together with some future research directions in various aspects.

\section{SYNTHESIS OF MCS}

In this section, we briefly overview the synthesis of metal oxide MCs by several different approaches. As the details of the synthesis procedures for and formation mechanisms of MCs are beyond the scope of this article, we request interested readers to refer to the comprehensive reviews cited in Introduction section. ${ }^{6-11}$

a
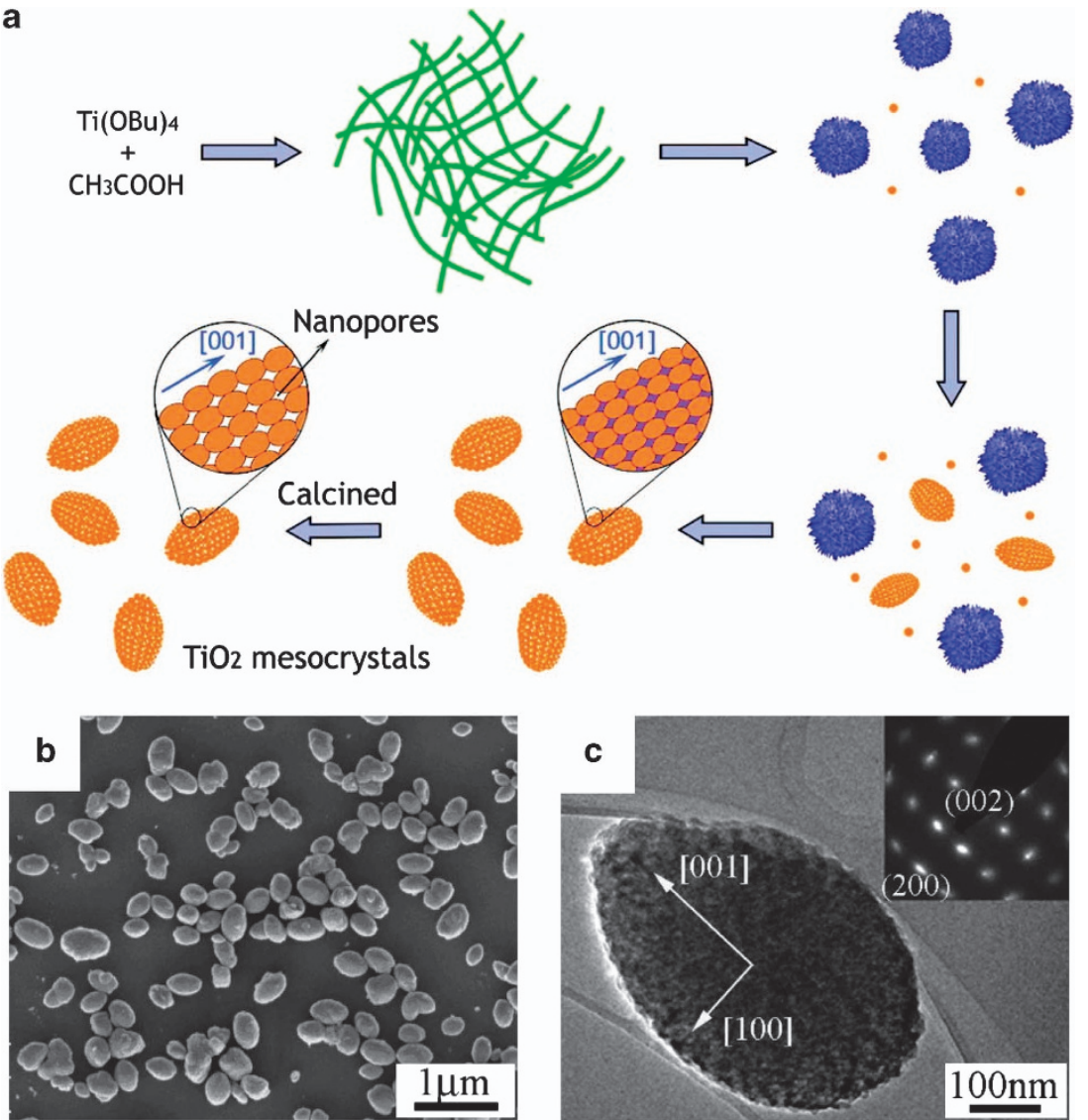

Figure 2 (a) Schematic illustration of the formation of spindle-shaped anatase $\mathrm{TiO}_{2}$ mesocrystals (MCs). (b) Scanning electron microscopy (SEM) and (c) transmission electron microscopy (TEM) images of $\mathrm{TiO}_{2} \mathrm{MCs}$. Reprinted with permission from reference Ye et al. ${ }^{16}$ Copyright 2011 American Chemical Society. 
The method most commonly used to synthesize MC materials is based on hydrothermal/solvothermal treatments in which a solution is maintained at a specific temperature and aged for a specific period of time. The resulting precipitates are then collected and washed to remove impurities. In some cases, the precipitates require further annealing. For example, the Qi group synthesized spindle-shaped anatase $\mathrm{TiO}_{2} \mathrm{MCs}$ by the solvothermal treatment of a solution of tetrabutyl titanate in acetic acid and subsequent calcinations. As illustrated in Figure 2a, the reaction between tetrabutyl titanate and acetic acid first forms unstable titanium acetate complexes by ligand exchange/substitution, concomitant with the release of butanol. ${ }^{16}$ The concomitant Ti-O-Ti condensation forms transient amorphous fiberlike precursors. Flower-like precursors are then produced at the expense of the transient precursors and release soluble titaniumcontaining species for the nucleation and growth of anatase NCs. These NCs undergo oriented aggregation along the [001] direction, consequently resulting in the formation of spindle-shaped anatase MCs (Figures $2 \mathrm{~b}$ and $\mathrm{c}$ ). The Brunauer-Emmett-Teller surface area and pore volume of the synthesized $\mathrm{TiO}_{2} \mathrm{MCs}$ were $114 \mathrm{~m}^{2} \mathrm{~g}^{-1}$ and $0.14 \mathrm{~m}^{3} \mathrm{~g}^{-1}$, respectively. Further, using the solvothermal method, $\mathrm{Li}$ and co-workers ${ }^{17}$ synthesized single crystal-like anatase $\mathrm{TiO}_{2}$ MCs with a high surface area of $180 \mathrm{~m}^{2} \mathrm{~g}^{-1}$ and a uniform pore diameter of $3.4 \mathrm{~nm}$. These $\mathrm{TiO}_{2} \mathrm{MCs}$ had either massive or granular structures in which most of the high-energy $\{001\}$ surfaces were hidden in the bulk.
The O'Brien group were the first to prepare anatase $\mathrm{TiO}_{2} \mathrm{MCs}$ via the topotactic transformation of $\mathrm{NH}_{4} \mathrm{TiOF}_{3}$ crystals. ${ }^{13}$ The topotactic transformation is a solid-state transformation in which the final product is structurally and orientationally related to the starting material. Figure 3 illustrates the topotactic transformation of $\mathrm{NH}_{4} \mathrm{TiOF}_{3}$ to anatase $\mathrm{TiO}_{2} \mathrm{MC}$. As the structures of $\mathrm{NH}_{4} \mathrm{TiOF}_{3}$ and anatase $\mathrm{TiO}_{2}$ are very similar, the positions of $\mathrm{Ti}$ atoms in the $\{001\}$ planes are well matched with each other. Using a similar synthesis strategy, Yu et al. ${ }^{19}$ synthesized layered anatase $\mathrm{TiO}_{2}$ nanosheets with exposed $\{001\}$ facets by a simple hydrothermal method, followed by calcination.

In 2012, Bian et al. ${ }^{21}$ significantly improved the synthesis method for anatase $\mathrm{TiO}_{2}$ MCs with dominant $\{001\}$ facets. Their improved method is illustrated in Figure 4a; plate-like $\mathrm{TiO}_{2} \mathrm{MCs}$ are obtained by annealing a thin layer of an aqueous solution containing $\mathrm{TiF}_{4}$, $\mathrm{NH}_{4} \mathrm{~F}$ and $\mathrm{NH}_{4} \mathrm{NO}_{3}$ (without surfactants) on a silicon wafer. In this one-step annealing process, the material undergoes changes in two stages. First, the precursors of $\mathrm{Ti}^{4+}, \mathrm{F}^{-}, \mathrm{NH}^{4+}$ and $\mathrm{H}_{2} \mathrm{O}$ begin a series of combination reactions during evaporation of water at low temperatures to form $\mathrm{NH}_{4} \mathrm{TiOF}_{3}$. With further increase in annealing temperature, $\mathrm{NH}_{4} \mathrm{TiOF}_{3}$ is topotactically transformed into anatase $\mathrm{TiO}_{2}$. When large amounts of $\mathrm{N}, \mathrm{H}$ and $\mathrm{F}$ atoms are removed, the volume of nanoparticles decreases and gaps or pores are formed between nanoparticles, resulting in the formation of porous $\mathrm{TiO}_{2}$

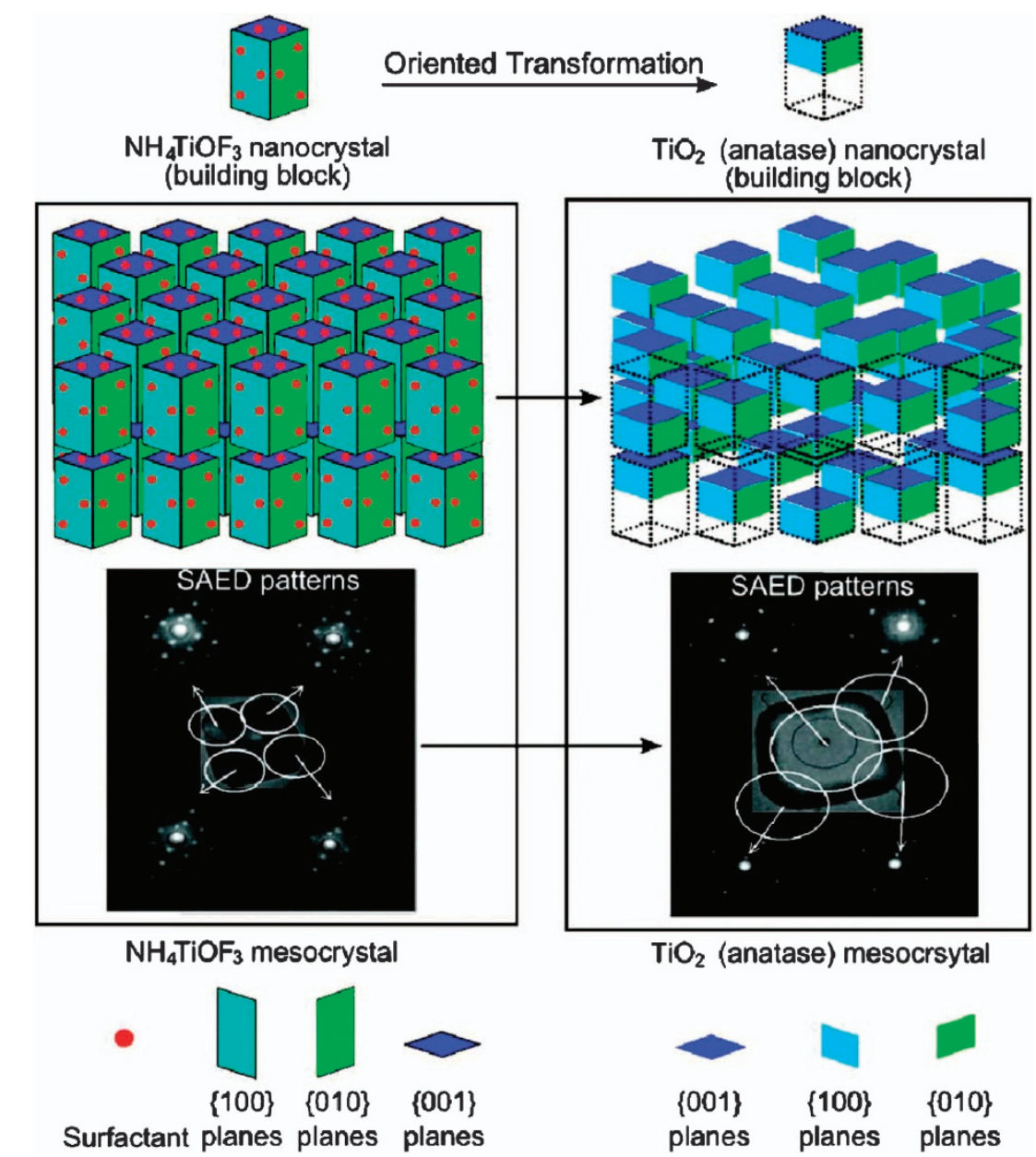

Figure 3 Schematic illustration of the topotactic transformation of $\mathrm{NH}_{4} \mathrm{TiOF}_{3}$ to anatase $\mathrm{TiO}_{2}$ mesocrystal (MC). Reprinted with permission from reference Zhou et al. ${ }^{13}$ Copyright 2008 American Chemical Society. 
a
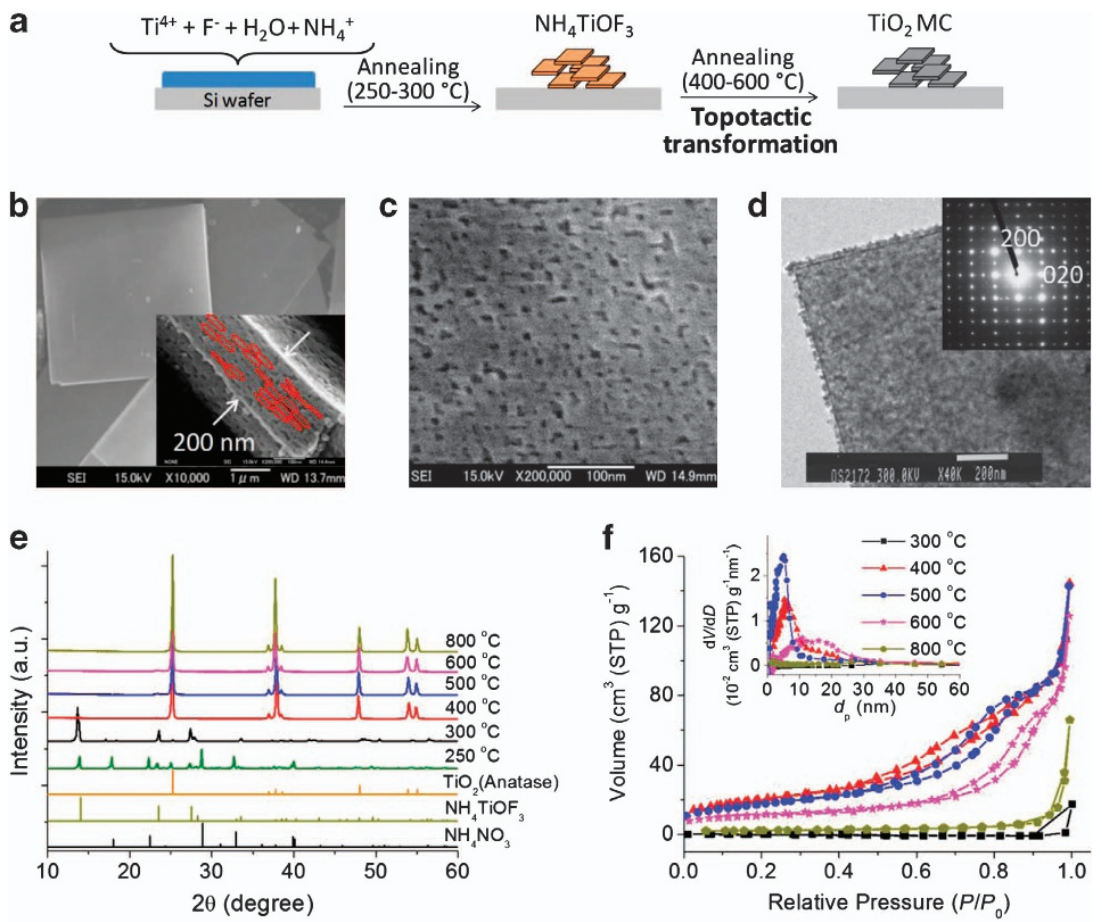

Figure 4 (a) Formation of $\mathrm{NH}_{4} \mathrm{TiOF}_{3}$ at low annealing temperatures $\left(250-300^{\circ} \mathrm{C}\right.$ ) and topotactic transformation from $\mathrm{NH}_{4} \mathrm{TiOF}_{3}$ to $\mathrm{TiO}_{2}$ mesocrystals $(\mathrm{MCs})$ at higher annealing temperatures. (b) Scanning electron microscopy (SEM) images of $\mathrm{TiO}_{2} \mathrm{MCs}$ annealed at $500^{\circ} \mathrm{C}$ showing a plate-like morphology. Inset shows assembled nanocrystals (NCs) on the lateral surface of $\mathrm{TiO}_{2} \mathrm{MC}$. (c) Magnified SEM image of a crystal surface revealing a porous structure. (d) Transmission electron microscopy (TEM) image of a representative crystal showing a mesoporous structure, and selected-area electron diffraction (SAED) pattern (inset) showing single-crystal diffraction along the anatase [001] zone axis. (e) X-ray diffraction (XRD) patterns and (f) $\mathrm{N}_{2}$ adsorption-desorption isotherms and pore size distribution (inset) of the products obtained at different annealing temperatures. Reprinted with permission from reference Bian et al. ${ }^{21}$ Copyright 2012 American Chemical Society.

MCs that consist of anatase single-crystalline nanoparticles with the $\{001\}$ surfaces as dominant facets.

They characterized the structures of the synthesized $\mathrm{TiO}_{2} \mathrm{MCs}$ by scanning electron microscopy (SEM) and transmission electron microscopy. The $\mathrm{TiO}_{2}$ MCs showed a plate-like structure several micrometers in size and $50-300 \mathrm{~nm}$ in thickness (Figure $4 \mathrm{~b}$ ). The MCs were composed of an ordered alignment of anatase $\mathrm{TiO}_{2} \mathrm{NCs}$ with an average size of approximately $40 \mathrm{~nm}$. A porous structure with pore diameters of several nanometers was confirmed by highresolution scanning electron microscopy and transmission electron microscopy images (Figures $4 \mathrm{c}$ and $\mathrm{d}$ ). It is worth mentioning here that a selected-area electron diffraction pattern of the crystal (inset) corresponded to single-crystal anatase along the [001] zone axis, thus suggesting the formation of anatase $\mathrm{TiO}_{2}$ with the $\{001\}$ facet exposed. An oriented arrangement of NCs decreases the grain boundaries in a sample. The pure phase of anatase was thus retained after calcination at $800^{\circ} \mathrm{C}$. The enhanced phase stability was explained by the assumption that the transformation to the rutile phase was inhibited by the elimination of interfacial nucleation sites. ${ }^{16}$

To understand the formation mechanism of anatase $\mathrm{TiO}_{2} \mathrm{MCs}$, they compared the scanning electron microscopy images, X-ray diffraction patterns, $\mathrm{N}_{2}$ adsorption-desorption isotherms and pore size distribution of the samples obtained at different synthesis temperatures (Figures $4 \mathrm{e}$ and $\mathrm{f}$ ). $\mathrm{NH}_{4} \mathrm{TiOF}_{3}$ growth started at $250{ }^{\circ} \mathrm{C}$ with a mixture $\mathrm{NH}_{4} \mathrm{TiOF}_{3}$ and $\mathrm{NH}_{4} \mathrm{NO}_{3}$ during the evaporation of water (Figure $4 \mathrm{e}$ ). Pure $\mathrm{NH}_{4} \mathrm{TiOF}_{3}$ with a plate-like structure was observed at $300^{\circ} \mathrm{C}$, but it did not have any pore structure on the surface and its specific surface area was very low $\left(\sim 0.4 \mathrm{~m}^{2} \mathrm{~g}^{-1}\right)$ (Figure $4 \mathrm{f}$ ). After annealing at $400{ }^{\circ} \mathrm{C}$, the obtained product was pure anatase $\mathrm{TiO}_{2}$ (Figure 4e) and had a porous structure with a specific surface area of $74 \mathrm{~m}^{2} \mathrm{~g}^{-1}$ and a pore size of approximately $5 \mathrm{~nm}$. Furthermore, no apparent change in morphology was observed, indicating the topotactic transformation from $\mathrm{NH}_{4} \mathrm{TiOF}_{3}$ to $\mathrm{TiO}_{2}$ by the removal of $\mathrm{N}, \mathrm{H}$ and $\mathrm{F}$ atoms from the crystal lattice. This removal of atoms resulted in the creation of space between $\mathrm{TiO}_{2} \mathrm{NCs}$, and thus, a porous structure was formed in the crystal. Upon further increasing the calcination temperature, the morphology and crystalline phase of $\mathrm{TiO}_{2}$ remained unchanged, while the mutual fusion of NCs led to an increase in the particle size, a decrease in the specific surface area and an increase in the pore size (Figure 4f).

Another important progress is the formation of MCs via electrochemical deposition. ${ }^{46,49}$ For example, Fang et al. ${ }^{46}$ reported an external electric field-driven particle-mediated bottom-up approach for synthesis of $\mathrm{Ag}_{2} \mathrm{O}$ MCs with different morphologies. Figure 5 shows the scanning electron microscopy images of the as-prepared $\mathrm{Ag}_{2} \mathrm{O}$ MCs under different applied potentials and growth times. The morphologies of the products obtained under different conditions are remarkably different (rhombic hexahedron, cube and dodecahedron), and the rough surface of MCs reveals a nonclassical crystallization process (insets of Figure 5).

An external magnetic field has also been applied to induce the selfassembly of $\gamma-\mathrm{Fe}_{2} \mathrm{O}_{3}$ nanocubes into micrometer-sized MC structures. ${ }^{41}$ The thickness of the MCs is controllable by varying the concentration of the nanoparticle dispersion as well as the duration of the applied magnetic field. 

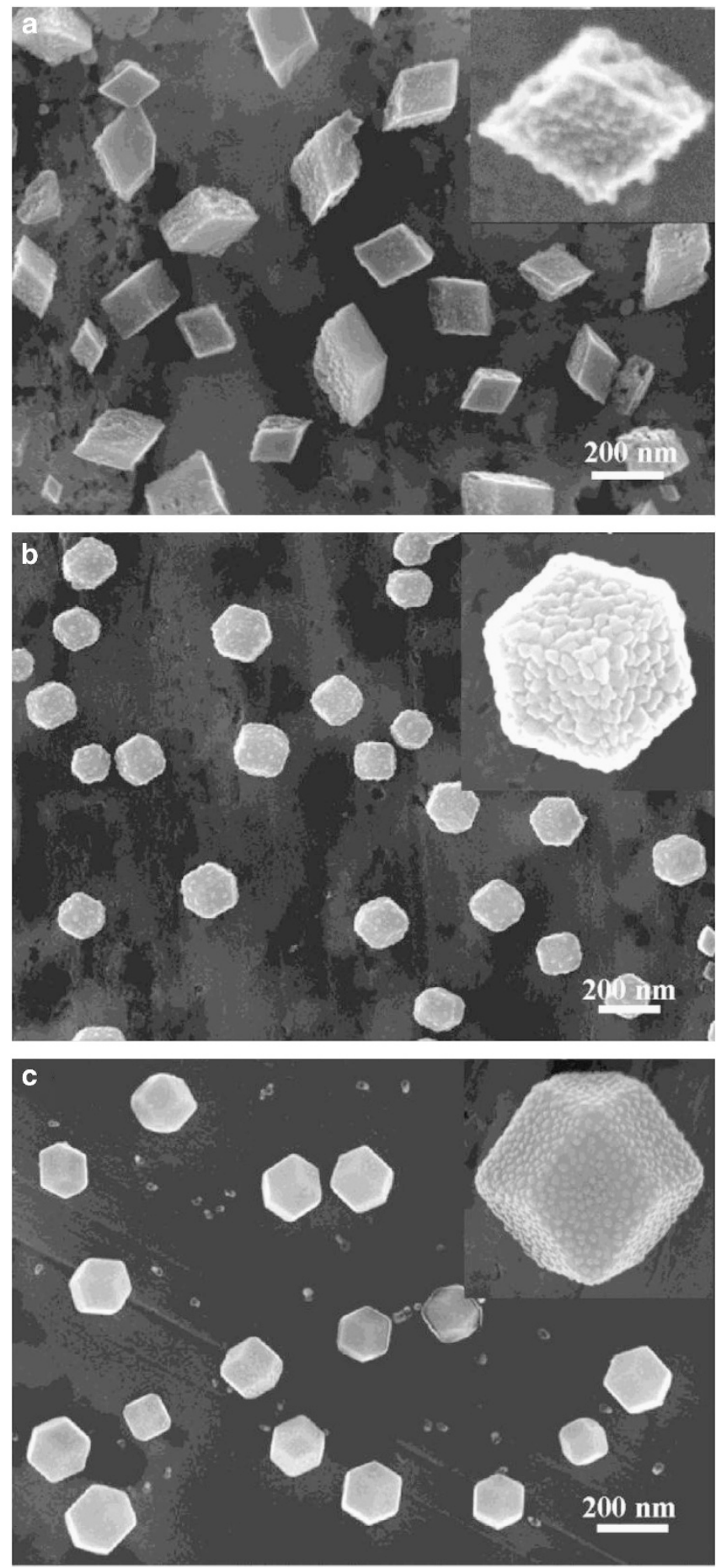

Figure 5 Scanning electron microscopy (SEM) images of $\mathrm{Ag}_{2} \mathrm{O}$ mesocrystals (MCs) synthesized at silver ion concentration of $1 \mathrm{~mm}$, applied potential and growth time of (a) $30 \mathrm{~V}$ and $3 \mathrm{~min}$, (b) $15 \mathrm{~V}$ and $3 \mathrm{~min}$ and (c) $5 \mathrm{~V}$ and $5 \mathrm{~min}$. Reprinted with permission from reference Fang et al. ${ }^{46}$ Copyright 2010 Elsevier BV.

\section{OPTICAL PROPERTIES OF MCS}

MCs are expected to exhibit some interesting and unique optical properties owing to their structural features. Wu et al. ${ }^{26}$ synthesized core-shell-structured $\mathrm{ZnO} \mathrm{MC}$ microspheres by a hydrothermal method in the presence of a water-soluble polymer. The whole surface of these MCs was composed of densely packed $\mathrm{ZnO}$ nanoplatelets aligned perpendicularly to the microspheres. Interestingly, these $\mathrm{ZnO} \mathrm{MCs}$ exhibited strong mechanical resonance and radiative emission at $\sim 0.36 \mathrm{THz}$ under $514.5-\mathrm{nm}$ continuous-wave laser irradiation. This property originated from the laser-induced coherent vibration of the $\mathrm{ZnO}$ nanoplatelets.

$\mathrm{Hu}$ et al. ${ }^{84}$ demonstrated that $\operatorname{Ag} \operatorname{In}\left(\mathrm{WO}_{4}\right)_{2}$ MCs exhibit a white emission in the visible region when excited by $460-\mathrm{nm}$ light. Their photoluminescence (PL) strongly correlated with the surface nanostructures of outgrowths; a larger amount of outgrowths led to stronger emission intensities. The MCs with high surface-to-volume ratios had more surface defects, which were responsible for the radiative recombination of charge carriers. In addition, Li et al. ${ }^{24}$ found that the PL properties of hollow-type $\mathrm{ZnO}$ MCs are largely governed by the number and nature of defects in the $\mathrm{ZnO}$ lattice.

Bian et al. ${ }^{85}$ investigated the recombination of photogenerated electrons and holes in plate-like $\mathrm{TiO}_{2} \mathrm{MCs}$ that yields distinct PL in the visible region. Figure 6a shows a typical emission image acquired for two partially overlapping $\mathrm{TiO}_{2} \mathrm{MCs}$ during $380-\mathrm{nm}$ photoexcitation in ambient air. Spectral measurements revealed a broad emission band at the center positions of the crystal at around $450-600 \mathrm{~nm}$ (Figure 6b), which originated from surface states. ${ }^{86,87}$ The average PL lifetimes of $\mathrm{TiO}_{2} \mathrm{MCs}$ and NCs were around 5.9 and $2.0 \mathrm{~ns}$, respectively (Figure 6c). Shorter (longer) PL lifetime of the samples indicates relatively faster (slower) charge recombination. Thus, it was concluded that the MC superstructure significantly improved charge separation efficiency. They also found that the average lifetime measured at the center of the MCs (5.5 ns) was slightly shorter than that measured at their edge $(6.9 \mathrm{~ns})$. The location-dependent nature of PL implied that charges trapped near the edge were subjected to a different recombination probability as compared with those trapped at the center.

\section{ELECTRON TRANSPORT IN MC}

Experiments on a single assembly of NCs revealed the superior physicochemical properties of ordered superstructures that are unattainable using conventional disordered systems. To explore the intricate relationship between structure and function, Bian et al. ${ }^{21}$ investigated the photoconductivity of individual $\mathrm{TiO}_{2} \mathrm{MCs}$ by means of conductive atomic force microscopy, with the instrument equipped with a UV light source (Figure 7a). As shown in Figures 7b, a significant photocurrent response was observed in case of UV irradiation on a single plate-like $\mathrm{TiO}_{2} \mathrm{MC}$ on an indium tin oxide electrode, while there was no measurable current response without UV irradiation. From the thickness dependence of the photocurrent, the photoconductivity was calculated to be $2 \times 10^{-2} \Omega^{-1} \mathrm{~m}^{-1}$ in air, which was several orders greater than that of aggregated $\mathrm{TiO}_{2} \mathrm{NCs}$ with a similar size $(\sim 200 \mathrm{~nm})$ under the same conditions (Figure $7 \mathrm{~b}$ ). This result suggested that electron transport ability in $\mathrm{TiO}_{2} \mathrm{MCs}$ was largely improved possibly because of the intimate contact between NCs and/or between NCs and electrodes.

Single-molecule, single-particle fluorescence micro(spectro)scopy has emerged as a powerful tool for obtaining information about the structure and dynamics of individual objects. ${ }^{88,89}$ Bian et al. ${ }^{85}$ applied this technique to determine the location of reactive sites on plate-like $\mathrm{TiO}_{2}$ MCs by using a redox-responsive fluorogenic probe. By accepting electrons from photoexcited $\mathrm{TiO}_{2}$, nonfluorescent 8-(3,4dinitrophenyl)-1,3,5,7-tetramethyl-4,4-difluoro-4-bora-3a,4a-diaza-sindacene (DN-BODIPY; fluorescence quantum yield $\Phi_{\mathrm{fl}}<10^{-4}$ in methanol) was reduced to form highly fluorescent 4-hydroxyamino3-nitrophenyl-BODIPY (HN-BODIPY; $\Phi_{\mathrm{fl}}=0.50$ in methanol) 
a

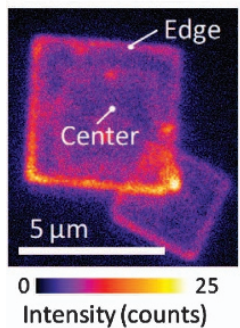

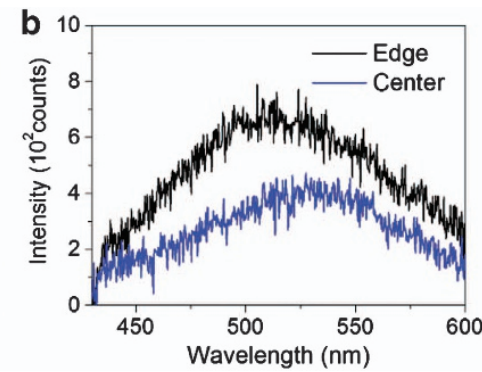

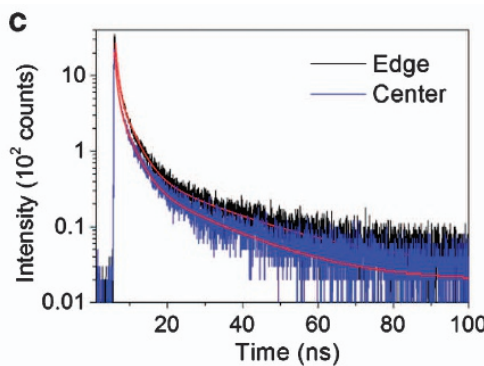

Figure 6 (a) Photoluminescence (PL) image of $\mathrm{TiO}_{2}$ mesocrystals (MCs) immobilized on a quartz glass (excitation wavelength: $380 \mathrm{~nm}$ ). (b) PL spectra and (c) decay profiles observed at the center and edge positions on $\mathrm{TiO}_{2} \mathrm{MCs}$. The red curves indicate multiexponential curves fitted to the kinetic trace. Reprinted with permission from reference Bian et al. ${ }^{85}$ Copyright 2012 American Chemical Society.

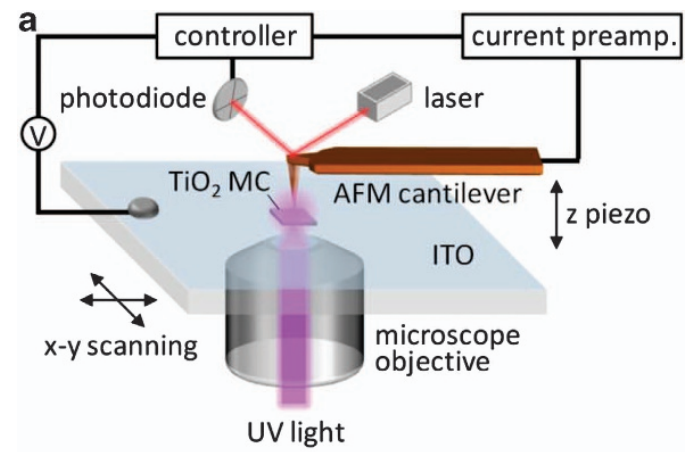

b

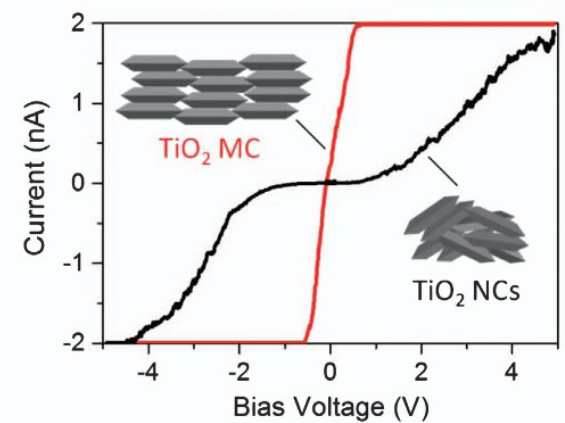

Figure 7 (a) A schematic of photoconductive atomic force microscopy (AFM). The platinum AFM tip was used to measure the surface topography and photocurrent under bias potential. The ultraviolet (UV) light is focused on the device through the indium tin oxide (ITO)-coated cover glass using an inverted fluorescence microscope. (b) Typical current-voltage curves measured for $\mathrm{TiO}_{2}$ mesocrystal (MC) (red) and aggregated $\mathrm{TiO}_{2} \mathrm{NCs}$ (black) at constant UV intensity $\left(9 \mathrm{~mW} \mathrm{~cm}^{-2}\right)$. Reprinted with permission from reference Bian et al. ${ }^{21}$ Copyright 2012 American Chemical Society.

(Figure 8a). The locations of the reduction sites were determined via centroid analysis of each fluorescent spot obtained for individual MCs. As shown in Figures $8 \mathrm{~b}$ and c, most of the fluorescence spots, that is, catalytically active sites, were found to be located near the edges of the MCs. This interesting finding was consistent with the observation that $\mathrm{Au}$ and $\mathrm{Pt}$ nanoparticles were preferentially photodeposited at the edges of $\mathrm{TiO}_{2}$ MCs with $\{101\}$ facets (Figures $8 \mathrm{e}$ and $\mathrm{f}$ ). In addition, the average rate of the formation of fluorescent products on the basal surfaces decreased from 5.6 to 2.3 molecules $\mu \mathrm{m}^{-2} \mathrm{~s}^{-1}$ upon $\mathrm{Au}$ loading on $\mathrm{TiO}_{2} \mathrm{MCs}$, whereas the reaction rate on the lateral surfaces increased from 11 to 19 molecules $\mu \mathrm{m}^{-2} \mathrm{~s}^{-1}$ (Figure 8d). These differences strongly supported the mechanism in which photogenerated electrons on the basal surfaces of $\mathrm{TiO}_{2} \mathrm{MCs}$ can rapidly migrate to Au nanoparticles loaded on the lateral surfaces through the NC network. This anisotropic electron transport greatly improved the photocatalytic performance to be better than that of conventional disordered systems (Figures $8 \mathrm{~g}$ and $\mathrm{h}$ ). In fact, the metal-nanoparticle-loaded $\mathrm{TiO}_{2}$ MC composites exhibited higher photocatalytic activity than the NC-based composites. Further, the loading amounts of noble metals required to achieve $50 \%$ of the photocatalytic degradation of 4-chlorophenol were compared under the same experimental conditions. The optimum loading amounts of metals on $\mathrm{TiO}_{2} \mathrm{MCs}$ (for example, 0.04 and $0.2 \mathrm{wt} \%$ for $\mathrm{Au}$ and $\mathrm{Pt}$, respectively) were about 10 times lower than those on $\mathrm{TiO}_{2} \mathrm{NCs}$ (for example, 0.4 and $4.0 \mathrm{wt} \%$ for $\mathrm{Au}$ and $\mathrm{Pt}$, respectively). This is desirable for the practical use of $\mathrm{TiO}_{2}$ MCs as photocatalysts because of the high price of noble metals.

\section{LITHIUM STORAGE PROPERTIES OF MCS}

MCs can be used in Li-ion batteries as either anode or cathode materials. The MC structure provides not only facile electronic conduction but also fast $\mathrm{Li}$ ion transport between the MC electrode and electrolyte. For example, Ye et al. ${ }^{16}$ prepared anatase $\mathrm{TiO}_{2} \mathrm{MCs}$ (see Figure 2) and used them as an anode material for a high-power Li-ion battery. As shown in Figure 9, the MC electrode exhibited better rate capability than a $\mathrm{TiO}_{2}$ nanoparticle electrode at high current rates. The uniformly porous structure of MCs facilitated their contact with the electrolyte and hence was also advantageous for fast Li-ion transport. The $\mathrm{TiO}_{2}$ MCs delivered specific discharge capacities of 164.9 and $151.7 \mathrm{~mA} \mathrm{hg}^{-1}$ at 1 and $2{ }^{\circ} \mathrm{C}$, respectively; these values were larger than those reported for $\mathrm{TiO}_{2}$ hollow spheres and were comparable with those reported for mesoporous spheres.

Duan et al. ${ }^{40}$ prepared high-stability $\alpha-\mathrm{Fe}_{2} \mathrm{O}_{3}$ MCs by a facile solvothermal method without polymer additives, and evaluated the discharge cycling performance of an electrode fabricated using $\alpha-\mathrm{Fe}_{2} \mathrm{O}_{3} \mathrm{MCs}$ with different morphologies. Rhombic $\alpha-\mathrm{Fe}_{2} \mathrm{O}_{3} \mathrm{MCs}$ showed the best cycling stability owing to closed and intracrystalline porosity.

\section{PHOTOCATALYTIC PERFORMANCE OF MCS}

The design and preparation of mesoporous $\mathrm{TiO}_{2}$ photocatalysts have attracted increasing interest in recent years owing to their exceptional properties and widespread potential applications. Tartaj ${ }^{18}$ synthesized anatase $\mathrm{TiO}_{2}$ MCs that exhibited good photocatalytic activity for organics degradation under UV light irradiation owing to their high crystallinity. Owing to their unique structural features, $\mathrm{TiO}_{2} \mathrm{MCs}$ 
a
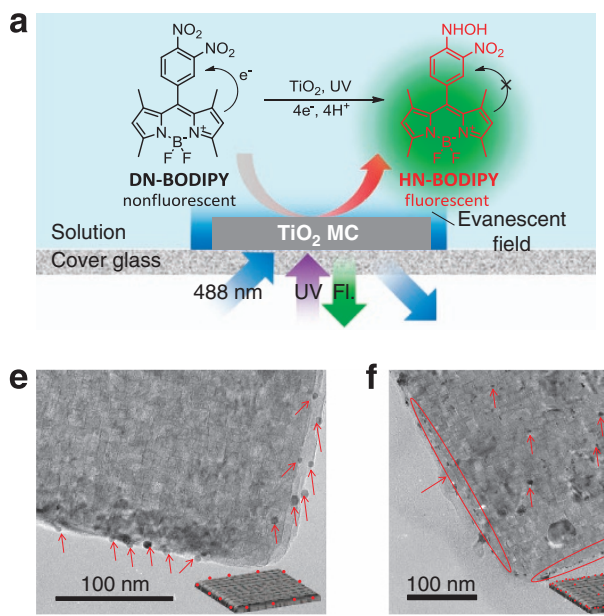

b

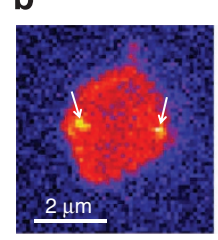

C

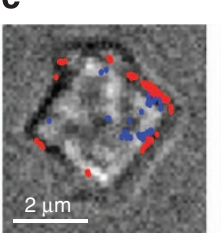

d

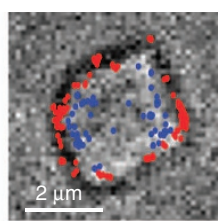

g
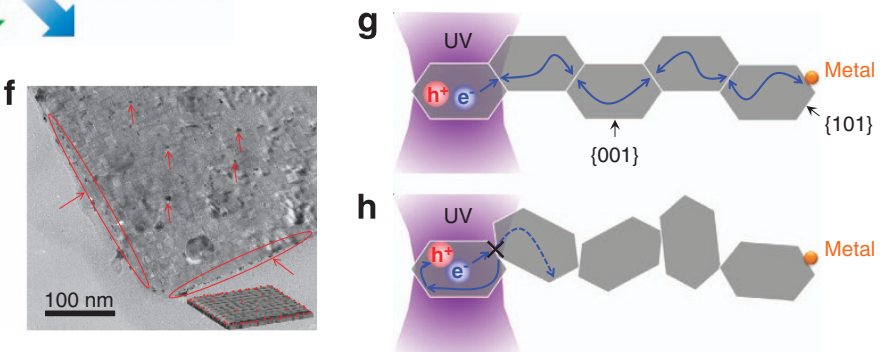

Figure 8 (a) Single-molecule fluorescence observation of photocatalytically generated fluorescent 4-hydroxyamino-3-nitrophenyl-BODIPY (HN-BODIPY) from nonfluorescent 8-(3,4-dinitrophenyl)-1,3,5,7-tetramethyl-4,4-difluoro-4-bora-3a,4a-diaza-s-indacene (DN-BODIPY) under ultraviolet (UV) light irradiation by total internal reflection fluorescence microscopy. (b) Fluorescence image of a $0.04 \mathrm{wt} \% \mathrm{Au} / \mathrm{TiO}_{2}$ mesocrystal (MC) particle immobilized on a cover glass in Ar-saturated DN-BODIPY solution $\left(0.5 \mu \mathrm{m}\right.$ in methanol) under $488-\mathrm{nm}$ laser $\left(0.1 \mathrm{~kW} \mathrm{~cm}{ }^{-2}\right)$ and UV light irradiation $\left(30 \mathrm{~mW} \mathrm{~cm}^{-2}\right)$. The arrows denote the locations of fluorescence spots. Optical transmission images of (c) $\mathrm{TiO}_{2} \mathrm{MC}$ and (d) 0.04 wt $\% \mathrm{Au}^{\mathrm{TiO}} \mathrm{O}_{2} \mathrm{MC}$ immobilized on a cover glass. The blue and red dots indicate the location of fluorescence bursts on the basal and lateral surfaces of the crystal, observed during $15 \mathrm{~s}$ of irradiation. Transmission electron microscopy (TEM) images of a representative crystal of (e) $0.04 \mathrm{wt} \% \mathrm{Au} / \mathrm{TiO}_{2} \mathrm{MC}$ and (f) $1.0 \mathrm{wt} \% \mathrm{Pt} / \mathrm{TiO} \mathrm{MC}_{2}$. Schematic illustration of electron transport processes in (g) structurally ordered $\mathrm{MC}$ and $(\mathbf{h})$ disordered nanocrystal $(\mathrm{NC})$ aggregation. The symbols $\mathrm{e}^{-}$and $\mathrm{h}^{+}$indicate photogenerated electrons and holes, respectively. Reprinted with permission from reference Bian et al. ${ }^{85}$ Copyright 2012 American Chemical Society.

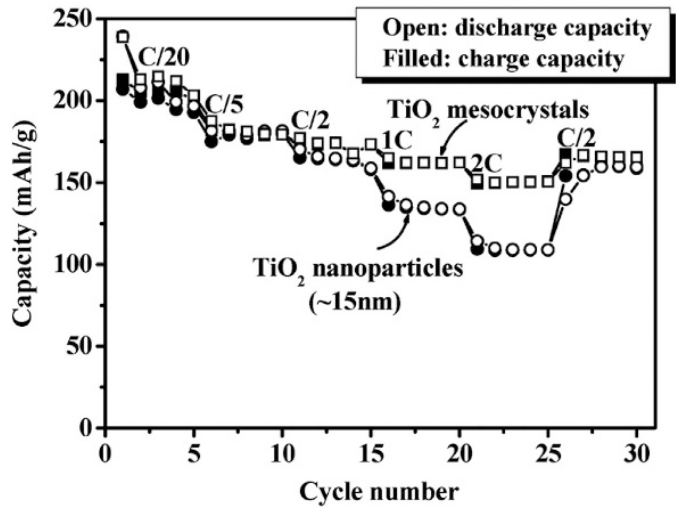

Figure 9 Rate capability of $\mathrm{TiO}_{2}$ mesocrystals (MCs) and nanoparticles from $\mathrm{C} / 20$ to $2 \mathrm{C}\left(1 \mathrm{C}=170 \mathrm{mAg}^{-1}\right)$ for five cycles. Reprinted with permission from reference Ye et al. ${ }^{16}$ Copyright 2011 American Chemical Society.

maintain a large specific surface area along with their good crystallinity.

$\mathrm{Yu}$ et al. prepared rutile $\mathrm{TiO}_{2}$ MCs by a microwave-assisted hydrothermal method. ${ }^{15}$ The $\mathrm{TiO}_{2}$ MCs are composed of rutile nanowires with an average aspect ratio of approximately 270 . These MCs showed good photocatalytic activity and stability for NO removal under UV or simulated solar light irradiation. Au modification of these $\mathrm{TiO}_{2}$ MCs led to a $50 \%$ improvement in their photocatalytic performance. The researchers ascribed the high photocatalytic ability to the following factors: (i) a high aspect ratio of the rutile $\mathrm{TiO}_{2}$ nanowires that allowed fast charge transport; (ii) a large effective surface area of the $\mathrm{TiO}_{2}$ MCs that resulted in easier diffusive transport of photogenerated holes to the target molecules; and (iii) efficient penetration of light and diffusion of NO molecules into the photocatalyst because of open pores.
The above-mentioned plate-like $\mathrm{TiO}_{2}$ MCs exhibited decent performance for the photocatalytic oxidation of 4-chlorophenol and rhodamine $\mathrm{B}$ as well as for the photocatalytic reduction of $\mathrm{Cr}^{6+}$ in water. ${ }^{21}$ The photocatalytic activities of these $\mathrm{TiO}_{2} \mathrm{MCs}$ exhibited a $100-300 \%$ enhancement relative to that of anatase $\mathrm{TiO}_{2}$ NCs with dominant $\{001\}$ facets and a similar specific surface area; the observed marked enhancement in activity could not be attributed to the specific surface area of the NCs. The photocatalytic performance of the $\mathrm{TiO}_{2} \quad \mathrm{MCs}$ was nearly similar to that of benchmark P25 $\mathrm{TiO}_{2}$ (Figures 10a-c). Time-resolved diffuse reflectance spectroscopy was used to directly measure the lifetime of a charge-separated state; this measure is a criterion for evaluating the efficiency of photocatalytic reactions. ${ }^{70}$ As shown in Figure 10d, the $\mathrm{TiO}_{2}$ MCs exhibited a broad transient absorption band in the visible to near-infrared range upon 355-nm laser excitation, which represented the overlapping of trapped holes (mainly 440-600 nm) and trapped electrons (mainly $660-900 \mathrm{~nm}){ }^{70} 4$-(Methylthio)phenyl methanol (MTPM) was then selected as the probe molecule to estimate the lifetime of the charge-separated state. ${ }^{70}$ As can be clearly seen in Figure 10e, the 550-nm absorption band of the MTPM radical cation $\left(\mathrm{MTPM}^{\bullet+}\right.$ ) was indicative of one-electron oxidation of adsorbed MTPM by photogenerated holes. The half-lives of $\mathrm{MTPM}^{\bullet}+$ were determined to be $\sim 2 \mu$ s for the $\mathrm{TiO}_{2} \mathrm{MC}$ systems, which was much longer than that of $\mathrm{TiO}_{2} \mathrm{NC}(\sim 0.5 \mu \mathrm{s})$. Hence, $\mathrm{TiO}_{2} \mathrm{MCs}$ could exhibit greatly increased photocatalytic activity owing to their superstructure that enhances charge separation.

Another interesting example is that of anatase $\mathrm{TiO}_{2} \mathrm{MCs}$ with different proportion of $\{001\}$ and $\{101\}$ facets synthesized by Chen et $a .^{22}$ The proportion of $\{101\}$ facets was tuned by adjusting the solvothermal periods. As shown in Figure 11, the $\mathrm{TiO}_{2}$ MCs with a high proportion of $\{101\}$ facets possessed higher photooxidation/ reduction activity than those with a lower proportion. This result was explained in terms of the synergistic effect of $\mathrm{Ti}^{3+}$ and the proportion of $\{101\}$ facets. In addition, the normalized photocatalytic activity of 

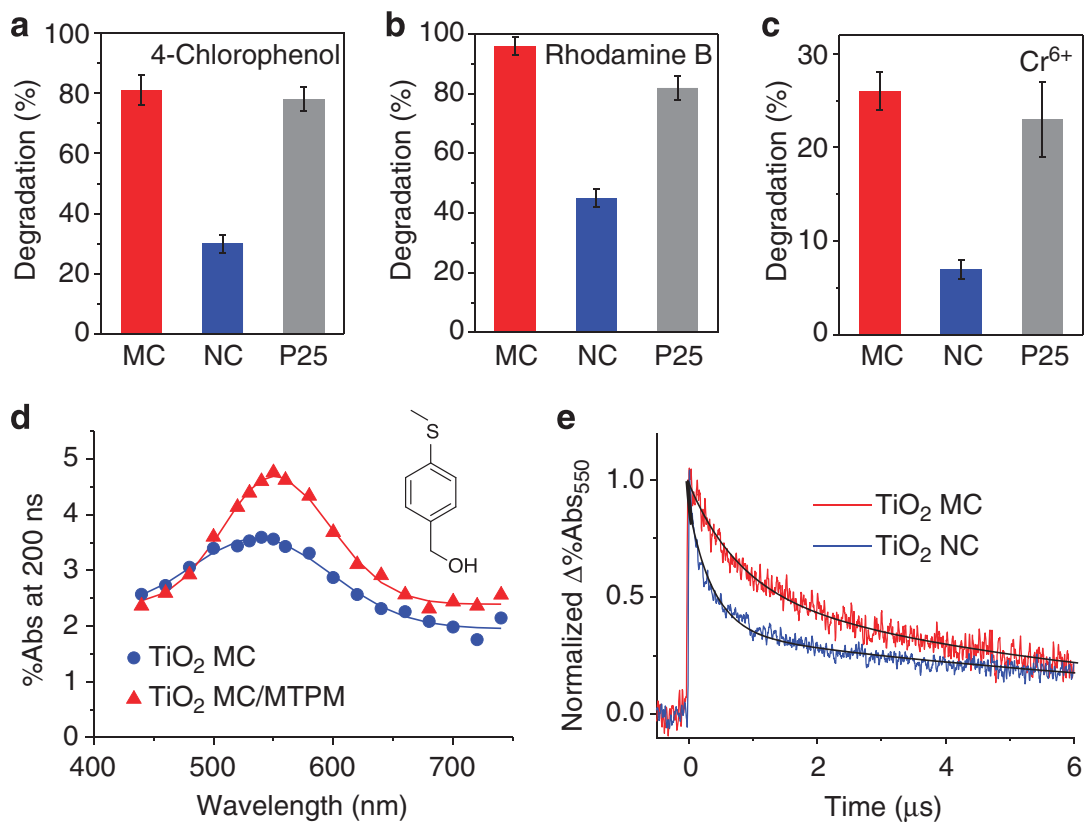

Figure 10 Photocatalytic degradation of (a) 4-chlorophenol, (b) rhodamine $\mathrm{B}$ and (c) $\mathrm{Cr}^{6+}$ in aqueous phase in the presence of different $\mathrm{TiO}_{2}$ samples. (d) Time-resolved diffuse reflectance spectra observed at $200 \mathrm{~ns}$ after a laser flash during the 355-nm laser flash photolysis of $\mathrm{TiO}_{2}$ mesocrystal $(\mathrm{MC})$ in the absence and presence of 4-(methylthio)phenyl methanol (MTPM; $10 \mathrm{mM}$ ) in acetonitrile. The inset indicates the molecular structure of MTPM. The absorption peak at around $550 \mathrm{~nm}$ is assigned to MTPM ${ }^{+}$. (e) Differential time traces of \%Abs at $550 \mathrm{~nm}$ obtained by subtracting the time trace observed in the absence of MTPM from that observed in the presence of MTPM $(10 \mathrm{mM})$ for different $\mathrm{TiO}_{2}$ samples in acetonitrile. Reprinted with permission from reference Bian et al. ${ }^{21}$ Copyright 2012 American Chemical Society.

$\mathrm{TiO}_{2}$ MCs was higher than that of $\mathrm{TiO}_{2}$ nanopolycrystals when the proportion of $\{101\}$ facets was equal; this indicated that the structural integrity of the crystals had a key role in determining the photocatalytic activity. Liu and co-workers ${ }^{90}$ synthesized hollow-type anatase $\mathrm{TiO}_{2}$ MCs with dominant $\{101\}$ facets via a new route by using $\mathrm{PO}_{4}{ }^{3-} / \mathrm{F}^{-}$as morphology-controlling agents. The hollow MCs were more active in $\mathrm{H}_{2}$ evolution from water splitting and $\mathrm{CH}_{4}$ generation from photoreduction of $\mathrm{CO}_{2}$, but were less active in $\mathrm{O}_{2}$ evolution from water splitting than hollow single crystals with a similar surface area. Interestingly, this reaction preference could be attributed to the fact that the hollow MCs had higher conduction and valence band edges than the hollow single crystals.

\section{MC-BASED COMPOSITE MATERIALS}

The direct growth method using topotactic transformation is suitable for constructing MC assemblies or layers on a variety of support materials. In 2008, Liu and Zeng ${ }^{91}$ developed a mild one-pot solution approach to prepare anatase $\mathrm{TiO}_{2}$ MCs on multiwalled carbon nanotubes (CNTs) with controllable surface coverage, surface area, crystal orientation and $\mathrm{TiO}_{2} / \mathrm{CNTs}$ ratio. CNTs were mixed with a $\mathrm{TiF}_{4}$ aqueous solution and held over an ultrasonic water bath for $30 \mathrm{~min}$. The subsequent aging at $60{ }^{\circ} \mathrm{C}$ for $20 \mathrm{~h}$ produced CNTs covered with closely arranged $\mathrm{TiO}_{2}$ crystallites with sizes in the range 2-4 nm (Figures $12 \mathrm{a}$ and $\mathrm{b}$ ). The as-prepared $\mathrm{TiO}_{2} / \mathrm{CNTs}$ nanocomposites showed better performance for photocatalytic degradation of an organic dye than P25 and CNTs because of (i) the high specific surface area that provided abundant adsorption sites for reactants; (ii) the porous structure that allowed efficient transport of reactants and products; (iii) the oriented arrangement of $\mathrm{TiO}_{2} \mathrm{NCs}$ that minimized light reflections and allowed light transmission to deeper parts of the catalyst; and (iv) surface defect sites and conductive CNTs support

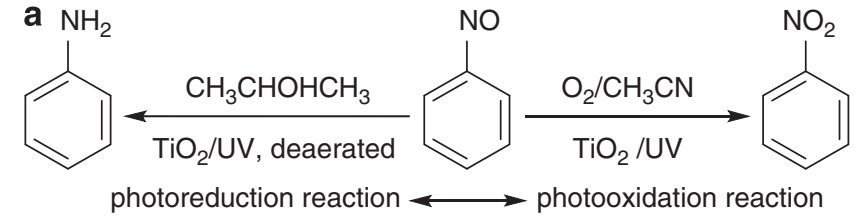

b

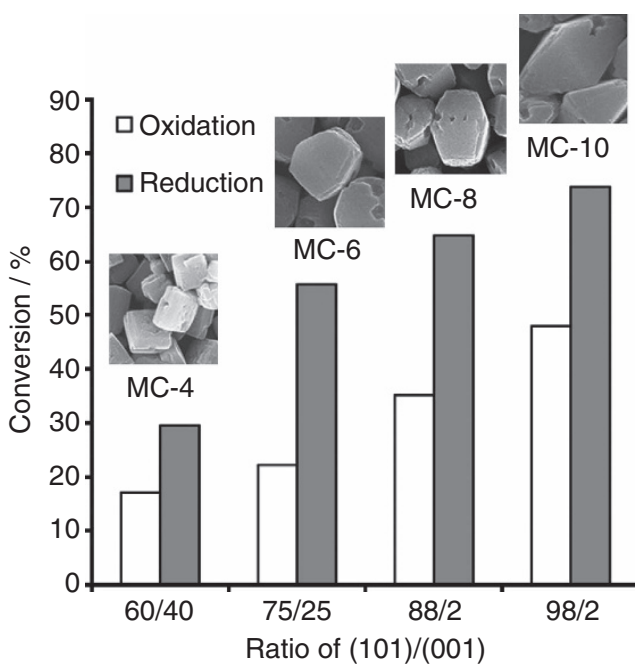

Figure 11 (a) Photocatalytic reduction and oxidation reaction of nitrosobenzene under different conditions. (b) Photocatalytic activity of different $\mathrm{TiO}_{2}$ mesocrystals (MCs) with various proportions of (001) and (101) facets. The inset shows scanning electron microscopy (SEM) images of the sample (image size: $1 \times 1 \mu \mathrm{m}$ ). Reprinted with permission from reference Chen et al. ${ }^{22}$ Copyright 2012 WILEY-VCH Verlag GmbH \& Co. KGaA, Weinheim. 

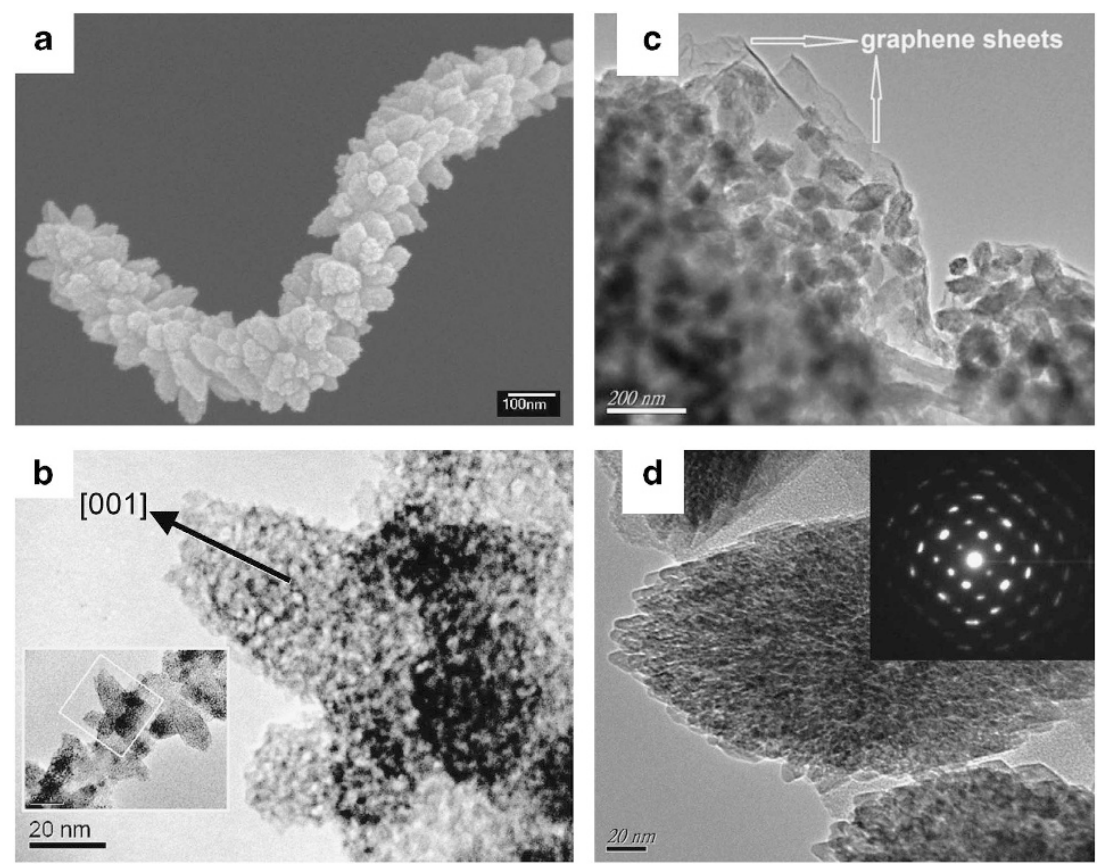

Figure 12 (a) Field emission scanning electron microscopy (FESEM) and (b) transmission electron microscopy $(\mathrm{TEM})$ image of mesoporous $\mathrm{TiO}_{2} / \mathrm{carbon}$ nanotube (CNT) nanocomposites. The examined location is indicated with a frame in the inset image. Reprinted with permission from reference Liu and Zeng ${ }^{91}$. Copyright 2008 American Chemical Society. (c, d) TEM images of graphene (GR)- $\mathrm{TiO}_{2}$ composites. Inset in panel (d) shows a selected-area electron diffraction (SAED) pattern of the composites. Reprinted with permission from reference Yang et al.92 Copyright 2013 Elsevier BV.

that may have served as electron reservoirs to suppress the recombination of electron-hole pairs. Yang et al. ${ }^{92}$ prepared graphene- $\mathrm{TiO}_{2}$ MC composites by a facile template-free process based on a combination of sol-gel and solvothermal methods (Figures $12 \mathrm{c}$ and d). The resulting products exhibited a uniform distribution of nanoporous anatase $\mathrm{TiO}_{2} \mathrm{MCs}$ on the graphene sheets. Composites prepared in the presence of different amounts of graphene oxide exhibited higher photocatalytic activity for photocatalytic degradation of rhodamine B than pure $\mathrm{TiO}_{2}$ MCs and P25.

\section{SUMMARY AND PERSPECTIVES}

The focus of current researches in the field of nanoscience and nanotechnology is shifting from the synthesis of individual NCs to the preparation and characterization of their MC superstructures and the realization of their applications. Although self-assembly of NCs by utilizing nanoscale attractive forces provides a simple approach for the fabrication of MCs, the synthesis procedures are sometimes very complicated, and hence, their large-scale applications are limited. A highly reproducible, facile synthesis of MCs with a controlled shape and size is strongly desirable for fundamental research and practical applications. One of the alternative strategies for fabricating such MCs is top-down fabrication through topotactic transformation.

MCs are also an ideal platform for constructing multifunctional materials that incorporate a variety of functional materials. For instance, the development of composite MCs consisting of two or more different types of metal oxide NCs (for example, composites of p- and n-type semiconductors) opens up exciting new opportunities for designing and constructing much more efficient photocatalysts and photovoltaic devices. Such binary nanoparticle superstructures have been well developed for several metals and chalcogenides but not yet for semiconductor metal oxides. ${ }^{93-95}$
Experiments on a single-particle assembly have revealed that ordered superstructures produce a high yield of photogenerated charges and have high photoconductivity, which are difficult to achieve using traditional disordered systems consisting of crystalline nanoparticles owing to the inevitable occurrence of charge recombination at the internal interface. The Majima group used singlemolecule, single-particle fluorescence microscopy to show that photogenerated electrons could reach reactive sites over a micrometer distance and are preferentially trapped at the edge of plate-like $\mathrm{TiO}_{2}$ MCs, in which $\{101\}$ facets are predominantly exposed. ${ }^{21,85}$ This anisotropic electron transport significantly retarded the charge recombination with holes, thereby resulting in enhanced photocatalytic activity. The excellent charge/molecular transport properties of MCs thus hold great promise for energy conversion and storage applications. Further development of the synthesis methods for MCs and understanding of their fundamental properties will lead to the production of innovative materials with potential applications in energy conversion and storage, catalysis and sensing.

\section{CONFLICT OF INTEREST}

The authors declare no conflict of interest.

\section{ACKNOWLEDGEMENTS}

TM thanks to the WCU (World Class University) program through the National Research Foundation of Korea funded by the Ministry of Education, Science and Technology (R31-10035) for the support. This work has been partly supported by a Grant-in-Aid for Scientific Research (projects 25220806, 25810114, and others) from the Ministry of Education, Culture, Sports, Science and Technology (MEXT) of the Japanese Government. 
1 Caruso, F. (ed.) Colloids and Colloid Assemblies (Wiley-VCH, Weinheim, Germany, 2003).

2 Mann, S. Self-assembly and transformation of hybrid nano-objects and nanostructures under equilibrium and non-equilibrium conditions. Nat. Mater. 8, 781-792 (2009).

$3 \mathrm{Nie}, \mathrm{Z}$., Petukhova, A. \& Kumacheva, E. Properties and emerging applications of self assembled structures made from inorganic nanoparticles. Nat. Nanotechnol. 5, 15-25 (2010).

4 Liu, J.-W., Liang, H.-W. \& Yu, S.-H. Macroscopic-scale assembled nanowire thin films and their functionalities. Chem. Rev. 112, 4770-4799 (2012).

5 Cölfen, H. \& Antonietti, M. Mesocrystals and Nonclassical Crystallization (Wiley, West Sussex, England, 2008)

6 Cölfen, H. \& Antonietti, M. Mesocrystals: inorganic superstructures made by highly parallel crystallization and controlled alignment. Angew. Chem., Int. Ed. 44, 5576-5591 (2005)

7 Zhou, L. \& O'Brien, P. Mesocrystals: a new class of solid materials. Small. 4, 1566-1574 (2008)

8 Song, R.-Q. \& Cölfen, H. Mesocrystals-ordered nanoparticle superstructures. Adv. Mater. 22, 1301-1330 (2010)

9 Niederberger, M. \& Cölfen, H. Oriented attachment and mesocrystals: non-classical crystallization mechanisms based on nanoparticle assembly. Phys. Chem. Chem. Phys. 8, 3271-3287 (2006).

10 Zhou, L. \& O'Brien, P. Mesocrystals—properties and applications. J. Phys. Chem. Lett 3, 620-628 (2012).

11 Fang, J., Ding, B. \& Gleiter, H. Mesocrystals: syntheses in metals and applications. Chem. Soc. Rev. 40, 5347-5360 (2011)

12 Seto, J., Ma, Y., Davis, S. A., Meldrum, F., Gourrier, A., Kim, Y.-Y., Schilde, U. Sztucki, M., Burghammer, M., Maltsev, S., Jaeger, C. \& Coelfen, H. Structure-property relationships of a biological mesocrystal in the adult sea urchin spine. Proc. Natl Acad. Sci. USA 109, 3699-3704 (2012).

13 Zhou, L., Smyth-Boyle, D. \& O'Brien, P. A facile synthesis of uniform $\mathrm{NH}_{4} \mathrm{TiOF}_{3}$ mesocrystals and their conversion to $\mathrm{TiO}_{2}$ mesocrystals. J. Am. Chem. Soc. 130, 1309-1320 (2008)

14 Liu, S.-J., Gong, J.-Y., Hu, B. \& Yu, S.-H. Mesocrystals of rutile $\mathrm{TiO}_{2}$ : mesoscale transformation, crystallization, and growth by a biologic molecules-assisted hydrothermal process. Cryst. Growth Des. 9, 203-209 (2009).

15 Zhang, D., Li, G., Wang, F. \& Yu, J. C. Green synthesis of a self-assembled rutile mesocrystalline photocatalyst. Cryst. Eng. Commun. 12, 1759-1763 (2010).

16 Ye, J.-F., Liu, W., Cai, J.-G., Chen, S., Zhao, X.-W., Zhou, H.-H. \& Qi, L.-M. Nanoporous anatase $\mathrm{TiO}_{2}$ mesocrystals: additive-free synthesis, remarkable crystalline-phase stability and improved lithium insertion behavior. J. Am. Chem. Soc. 133, 933-940 (2011).

17 Bian, Z., Zhu, J., Wen, J., Cao, F., Huo, Y., Qian, X., Cao, Y., Shen, M., Li, H. \& Lu, Y. Single-crystal-like titania mesocages. Angew. Chem., Int. Ed. 50, 1105-1108 (2011).

18 Tartaj, P. Sub-100 nm TiO 2 mesocrystalline assemblies with mesopores: preparation, characterization, enzyme immobilization and photocatalytic properties. Chem. Commun. 47, 256-258 (2011).

$19 \mathrm{Yu}, \mathrm{H}$. , Tian, B. \& Zhang, J. Layered $\mathrm{TiO}_{2}$ composed of anatase nanosheets with exposed $\{001\}$ facets: facile synthesis and enhanced photocatalytic activity. Chem. Eur. J. 17, 5499-5502 (2011).

20 Cai, J., Ye, J., Chen, S., Zhao, X., Zhang, D., Chen, S., Ma, Y., Jin, S. \& Qi, L. Self cleaning, broadband and quasi-omnidirectional antireflective structures based on mesocrystalline rutile $\mathrm{TiO}_{2}$ nanorod arrays. Energy Environ. Sci. 5, 7575-7581 (2012).

21 Bian, Z., Tachikawa, T. \& Majima, T. Superstructure of $\mathrm{TiO}_{2}$ crystalline nanoparticles yields effective conduction pathways for photogenerated charges. J. Phys. Chem. Lett. 3, 1422-1427 (2012).

22 Chen, Q., Ma, W., Chen, C., Ji, H. \& Zhao, J. Anatase $\mathrm{TiO}_{2}$ mesocrystals enclosed by (001) and (101) facets: synergistic effects between $\mathrm{Ti}^{3+}$ and facets for their photocatalytic performance. Chem. Eur. J. 18, 12584-12589 (2012).

23 Zhou, L., Chen, J., Ji, C., Zhou, L. \& O'Brien, P. A facile solid phase reaction to prepare $\mathrm{TiO}_{2}$ mesocrystals with exposed $\{001\}$ facets and high photocatalytic activity. Cryst. Eng. Commun. 15, 5012-5015 (2013)

24 Li, Z., Gessner, A., Richters, J.-P., Kalden, J., Voss, T., Kuebel, C. \& Taubert, A. Hollow zinc oxide mesocrystals from an ionic liquid precursor (ILP). Adv. Mater. 20, 1279-1285 (2008).

25 Liu, Z., Wen, X. D., Wu, X. L., Gao, Y. J., Chen, H. T., Zhu, J. \& Chu, P. K. Intrinsic dipole-field-driven mesoscale crystallization of core-shell $\mathrm{ZnO}$ mesocrystal microspheres. J. Am. Chem. Soc. 131, 9405-9412 (2009).

26 Wu, X. L., Xiong, S. J., Liu, Z., Chen, J., Shen, J. C., Li, T. H., Wu, P. H. \& Chu, P. K Green light stimulates terahertz emission from mesocrystal microspheres. Nat. Nanotechnol. 6, 103-106 (2011).

27 Distaso, M., Klupp Taylor, R. N., Taccardi, N., Wasserscheid, P. \& Peukert, W. Influence of the counterion on the synthesis of $\mathrm{ZnO}$ mesocrystals under solvothermal conditions. Chem. Eur. J. 17, 2923-2930 (2011).

28 Distaso, M., Segets, D., Wernet, R., Taylor, R. K. \& Peukert, W. Tuning the size and the optical properties of $\mathrm{ZnO}$ mesocrystals synthesized under solvothermal conditions. Nanoscale 4, 864-873 (2012)

29 Hosono, E., Tokunaga, T., Ueno, S., Oaki, Y., Imai, H., Zhou, H. \& Fujihara, S. Crystalgrowth process of single-crystal-like mesoporous $\mathrm{ZnO}$ through a competitive reaction in solution. Cryst. Growth Des. 12, 2923-2931 (2012).

30 Liu, M.-H., Tseng, Y.-H., Greer, H. F., Zhou, W. \& Mou, C.-Y. Dipole field guided orientated attachment of nanocrystals to twin-brush $\mathrm{ZnO}$ mesocrystals. Chem. Eur. J. 18, 16104-16113 (2012).
31 Sun, S., Zhang, X., Zhang, J., Song, X. \& Yang, Z. Unusual designated-tailoring on zone-axis preferential growth of surfactant-free $\mathrm{ZnO}$ mesocrystals. Cryst. Growth Des. 12, 2411-2418 (2012)

32 Waltz, F., Wissmann, G., Lippke, J., Schneider, A. M., Schwarz, H.-C., Feldhoff, A., Eiden, S. \& Behrens, P. Evolution of the morphologies of zinc oxide mesocrystals under the influence of natural polysaccharides. Cryst. Growth Des. 12, 3066-3075 (2012).

33 Wang, H., Xin, L., Wang, H., Yu, X., Liu, Y., Zhou, X. \& Li, B. Aggregation-induced growth of hexagonal $\mathrm{ZnO}$ hierarchical mesocrystals with interior space: nonaqueous synthesis, growth mechanism, and optical properties. RSC Adv. 3, 6538-6544 (2013).

34 Wang, S.-S. \& Xu, A.-W. Template-free facile solution synthesis and optical properties of ZnO mesocrystals. Cryst. Eng. Commun. 15, 376-381 (2013).

35 Park, G.-S., Shindo, D., Waseda, Y. \& Sugimoto, T. Internal structure analysis of monodispersed pseudocubic hematite particles by electron microscopy. J. Colloid Interface Sci. 177, 198-207 (1996).

36 Fang, X.-L., Chen, C., Jin, M.-S., Kuang, Q., Xie, Z.-X., Xie, S.-Y., Huang, R.-B. \& Zheng, L.-S. Single-crystal-like hematite colloidal nanocrystal clusters: synthesis and applications in gas sensors, photocatalysis and water treatment. J. Mater. Chem. 19, 6154-6160 (2009)

37 An, Z., Zhang, J., Pan, S. \& Yu, F. Facile template-free synthesis and characterization of elliptic $\alpha-\mathrm{Fe}_{2} \mathrm{O}_{3}$ superstructures. J. Phys. Chem. C 113, 8092-8096 (2009).

38 Chen, J. S., Zhu, T., Li, C. M. \& Lou, X. W. Building hematite nanostructures by oriented attachment. Angew. Chem., Int. Ed. 50, 650-653 (2011).

39 Ma, J., Teo, J., Mei, L., Zhong, Z., Li, Q., Wang, T., Duan, X., Lian, J. \& Zheng, W. Porous platelike hematite mesocrystals: synthesis, catalytic and gas-sensing applications. J. Mater. Chem. 22, 11694-11700 (2012).

40 Duan, X., Mei, L., Ma, J., Li, Q., Wang, T. \& Zheng, W. Facet-induced formation of hematite mesocrystals with improved lithium storage properties. Chem. Commun. 48 12204-12206 (2012)

41 Ahniyaz, A., Sakamoto, Y. \& Bergström, L. Magnetic field-induced assembly of oriented superlattices from maghemite nanocubes. Proc. Natl Acad. Sci. USA 104, 17570-17574 (2007)

$42 \mathrm{He}, \mathrm{T}$., Chen, D. \& Jiao, X. Controlled synthesis of $\mathrm{C}_{3} \mathrm{O}_{4}$ nanoparticles through oriented aggregation. Chem. Mater. 16, 737-743 (2004).

43 Yang, H. G. \& Zeng, H. C. Self-construction of hollow $\mathrm{SnO}_{2}$ octahedra based on twodimensional aggregation of nanocrystallites. Angew. Chem. Int. Ed. 43, 5930-5933 (2004).

44 Zhuang, Z., Huang, F., Lin, Z. \& Zhang, H. Aggregation-induced fast crystal growth of $\mathrm{SnO}_{2}$ nanocrystals. J. Am. Chem. Soc. 134, 16228-16234 (2012).

45 Zhao, J., Tan, R., Guo, Y., Lu, Y., Xu, W. \& Song, W. SnO mesocrystals: additive-free synthesis, oxidation, and top-down fabrication of quantum dots. Cryst. Eng. Commun. 14, 4575-4577 (2012)

46 Fang, J., Leufke, P. M., Kruk, R., Wang, D., Scherer, T. \& Hahn, H. External electric field driven $3 \mathrm{D}$ ordering architecture of silver (I) oxide meso-superstructures. Nano Today 5, 175-182 (2010).

47 Liu, B. \& Zeng, H. C. Mesoscale organization of CuO nanoribbons: formation of "dandelions". J. Am. Chem. Soc. 126, 8124-8125 (2004).

48 Yao, W.-T., Yu, S.-H., Zhou, Y., Jiang, J., Wu, Q.-S., Zhang, L. \& Jiang, J. Formation of uniform $\mathrm{CuO}$ nanorods by spontaneous aggregation: selective synthesis of $\mathrm{CuO}, \mathrm{Cu}_{2} \mathrm{O}$, and $\mathrm{Cu}$ nanoparticles by a solid-liquid phase arc discharge process. J. Phys. Chem. B 109, 14011-14016 (2005)

49 Xu, M., Wang, F., Ding, B., Song, X. \& Fang, J. Electrochemical synthesis of leaf-like CuO mesocrystals and their lithium storage properties. RSC Adv. 2, 2240-2243 (2012).

50 Huang, F., Zhang, H. \& Banfield, J. F. Two-stage crystal-growth kinetics observed during hydrothermal coarsening of nanocrystalline ZnS. Nano Lett. 3, 373-378 (2003).

51 Yu, J. H., Joo, J., Park, H. M., Baik, S.-I., Kim, Y. W., Kim, S. C. \& Hyeon, T. Synthesis of quantum-sized cubic ZnS nanorods by the oriented attachment mechanism. J. Am. Chem. Soc. 127, 5662-5670 (2005).

52 Querejeta-Fernandez, A., Hernandez-Garrido, J. C., Yang, H., Zhou, Y., Varela, A. Parras, M., Calvino-Gamez, J. J., Gonzalez-Calbet, J. M., Green, P. F. \& Kotov, N. A. Unknown aspects of self-assembly of PbS microscale sperstructures. ACS Nano 6 , 3800-3812 (2012)

53 Cho, K.-S., Talapin, D. V., Gaschler, W. \& Murray, C. B. Designing PbSe nanowires and nanorings through oriented attachment of nanoparticles. J. Am. Chem. Soc. 127 7140-7147 (2005).

54 Nagaoka, Y., Chen, O., Wang, Z. \& Cao, Y. C. Structural control of nanocrystal super lattices using organic guest molecules. J. Am. Chem. Soc. 134, 2868-2871 (2012).

55 Fang, J., Ma, X., Cai, H., Song, X. \& Ding, B. Nanoparticle-aggregated 3D monocrystalline gold dendritic nanostructures. Nanotechnology 17, 5841-5845 (2006).

56 Giersig, M., Pastoriza-Santos, I. \& Liz-Marzán, L. M. Evidence of an aggregative mechanism during the formation of silver nanowires in $\mathrm{N}, \mathrm{N}$-dimethylformamide. J. Mater. Chem. 14, 607-610 (2004).

57 Fang, J., Ding, B. \& Song, X. Self-assembly mechanism of platelike silver mesocrystal. Appl. Phys. Lett. 91, 083108 (2007)

58 Cao, Y., Fan, J., Bai, L., Hu, P., Yang, G., Yuan, F. \& Chen, Y. Formation of cubic Cu mesocrystals by a solvothermal reaction. Cryst. Eng. Commun. 12, 3894-3899 (2010).

59 Yamauchi, Y., Momma, T., Fuziwara, M., Nair, S. S., Ohsuna, T., Terasaki, O., Osaka, T. \& Kuroda, K. Unique microstructure of mesoporous Pt (HI-Pt) prepared via direct physical casting in lyotropic liquid crystalline media. Chem. Mater. 17, 6342-6348 (2005).

$60 \mathrm{Li}, \mathrm{T}$. , You, H., Xu, M., Song, X. \& Fang, J. Electrocatalytic properties of hollow corallike platinum mesocrystals. ACS Appl. Mater. Interfaces 4, 6942-6948 (2012).

61 Huang, X., Tang, S., Yang, J., Tan, Y. \& Zheng, N. Etching growth under surface confinement: an effective strategy to prepare mesocrystalline Pd nanocorolla. J. Am Chem. Soc. 133, 15946-15949 (2011). 
62 Wohlrab, S., Pinna, N., Antonietti, M. \& Cölfen, H. Polymer-induced alignment of DL-alanine nanocrystals to crystalline mesostructures. Chem. Eur. J. 11, 2903-2913 (2005).

63 Medina, D. D. \& Mastai, Y. Synthesis of DL-alanine mesocrystals with a hollow morphology. Cryst. Growth Des. 8, 3646-3651 (2008).

64 Jiang, Y., Gong, H., Volkmer, D., Gower, L. \& Cölfen, H. Preparation of hierarchical mesocrystalline DL-lysine $\cdot \mathrm{HCl}$-poly(acrylic acid) hybrid thin films. Adv. Mater. 23, 3548-3552 (2011).

65 Huang, M., Schilde, U., Kumke, M., Antonietti, M. \& Cölfen, H. Polymer-induced selfassembly of small organic molecules into ultralong microbelts with electronic conductivity. J. Am. Chem. Soc. 132, 3700-3707 (2010).

66 Oaki, Y., Kotachi, A., Miura, T. \& Imai, H. Bridged nanocrystals in biominerals and their biomimetics: classical yet modern crystal growth on the nanoscale. Adv. Funct. Mater. 16, 1633-1639 (2006).

67 Fujishima, A., Zhang, X. \& Tryk, D. A. $\mathrm{TiO}_{2}$ photocatalysis and related surface phenomena. Surf. Sci. Rep. 63, 515-582 (2008).

68 Chen, X., Shen, S., Guo, L. \& Mao, S. S. Semiconductor-based photocatalytic hydrogen generation. Chem. Rev. 110, 6503-6570 (2010).

69 Yang, Z., Zhang, J., Kintner-Meyer, M. C. W., Lu, X., Choi, D., Lemmon, J. P. \& Liu, J. Electrochemical energy storage for green grid. Chem. Rev. 111, 3577-3613 (2011).

70 Tachikawa, T., Fujitsuka, M. \& Majima, T. Mechanistic insight into the $\mathrm{TiO}_{2}$ photocatalytic reactions: design of new photocatalysts. J. Phys. Chem. C 111, 5259-5275 (2007).

71 Liu, G., Yu, J. C., Lu, G. Q. \& Cheng, H.-M. Crystal facet engineering of semiconductor photocatalysts: motivations, advances and unique properties. Chem. Commun. 47, 6763-6783 (2011).

72 Zhou, K. \& Li, Y. Catalysis based on nanocrystals with well-defined facets. Angew. Chem., Int. Ed. 51, 602-613 (2012).

73 Yang, H. G., Sun, C. H., Qiao, S. Z., Zou, J., Liu, G., Smith, S. C., Cheng, H. M. \& Lu, G. $Q$. Anatase $\mathrm{TiO}_{2}$ single crystals with a large percentage of reactive facets. Nature 453, 638-641 (2008).

$74 \mathrm{Liu}, \mathrm{S}$., Yu, J. \& Jaroniec, M. Anatase $\mathrm{TiO}_{2}$ with dominant high-energy $\{001\}$ facets: synthesis, properties, and applications. Chem. Mater. 23, 4085-4093 (2011).

75 Crossland, E. J. W., Noel, N., Sivaram, V., Leijtens, T., Alexander-Webber, J. A. \& Snaith, H. J. Mesoporous $\mathrm{TiO}_{2}$ single crystals delivering enhanced mobility and optoelectronic device performance. Nature 495, 215-219 (2013).

76 Zheng, X., Kuang, Q., Yan, K., Qiu, Y., Qiu, J. \& Yang, S. Mesoporous $\mathrm{TiO}_{2}$ single crystals: facile shape-, size-, and phase-controlled growth and efficient photocatalytic performance. ACS Appl. Mater. Interfaces 5, 11249-11257 (2013).

77 Park, Y., Kim, W., Monllor-Satoca, D., Tachikawa, T., Majima, T. \& Choi, W. Role of interparticle charge transfers in agglomerated photocatalyst nanoparticles: demonstration in aqueous suspension of dye-sensitized $\mathrm{TiO}_{2}$. J. Phys. Chem. Lett. 4, 189-194 (2013).

78 Lakshminarasimhan, N., Bae, E. \& Choi, W. Enhanced photocatalytic production of $\mathrm{H}_{2}$ on mesoporous $\mathrm{TiO}_{2}$ prepared by template-free method: role of interparticle charge transfer. J. Phys. Chem. C 111, 15244-15250 (2007).

79 Lakshminarasimhan, N., Kim, W. \& Choi, W. Effect of the agglomerated state on the photocatalytic hydrogen production with in situ agglomeration of colloidal $\mathrm{TiO}_{2}$ nanoparticles. J. Phys. Chem. C 112, 20451-20457 (2008).

80 Choi, S. K., Kim, S., Lim, S. K. \& Park, H. Photocatalytic comparison of $\mathrm{TiO}_{2}$ nanoparticles and electrospun $\mathrm{TiO}_{2}$ nanofibers: effects of mesoporosity and interparticle charge transfer. J. Phys. Chem. C 114, 16475-16480 (2010).

81 Ismail, A. A. \& Bahnemann, D. W. Mesostructured $\mathrm{Pt} / \mathrm{TiO} \mathrm{O}_{2}$ nanocomposites as highly active photocatalysts for the photooxidation of dichloroacetic acid. J. Phys. Chem. C $115,5784-5791$ (2011)
82 Tirosh, S., Dittrich, T., Ofir, A., Grinis, L. \& Zaban, A. Influence of ordering in porous $\mathrm{TiO}_{2}$ layers on electron diffusion. J. Phys. Chem. B 110, 16165-16168 (2006).

83 Gonzalez-Vazquez, J. P., Morales-Florez, V. \& Anta, J. A. How important is working with an ordered electrode to improve the charge collection efficiency in nanostructured solar cells? J. Phys. Chem. Lett 3, 386-393 (2012).

84 Hu, B., Wu, L.-H., Zhao, Z., Zhang, M., Chen, S.-F., Liu, S.-J., Shi, H.-Y., Ding, Z.-J. \& Yu, S.-H. Hierarchical silver indium tungsten oxide mesocrystals with morphology-, pressure-, and temperature-dependent luminescence properties. Nano Res. 3, 395-403 (2010).

85 Bian, Z., Tachikawa, T., Kim, W., Choi, W. \& Majima, T. Superior electron transport and photocatalytic abilities of metal-nanoparticle-loaded $\mathrm{TiO}_{2}$ superstructures. J. Phys. Chem. C 116, 25444-25453 (2012).

86 Tachikawa, T., Ishigaki, T., Li, J.-G., Fujitsuka, M. \& Majima, T. Defect-mediated photoluminescence dynamics of $\mathrm{Eu}^{3+}$-doped $\mathrm{TiO}_{2}$ nanocrystals revealed at the single-particle or single-aggregate level. Angew. Chem., Int. Ed. 47, 5348-5352 (2008).

87 Tachikawa, T., Yamashita, S. \& Majima, T. Evidence for crystal-face-dependent $\mathrm{TiO}_{2}$ photocatalysis from single-molecule imaging and kinetic analysis. J. Am. Chem. Soc. 133, 7197-7204 (2011).

88 Tachikawa, T. \& Majima, T. Single-molecule, single-particle fluorescence imaging of $\mathrm{TiO}_{2}$-based photocatalytic reactions. Chem. Soc. Rev. 39, 4802-4819 (2010).

89 Tachikawa, T. \& Majima, T. Single-molecule, single-particle approaches for exploring the structure and kinetics of nanocatalysts. Langmuir. 28, 8933-8943 (2012).

90 Jiao, W., Wang, L., Liu, G., Lu, G. Q. \& Cheng, H.-M. Hollow anatase $\mathrm{TiO}_{2}$ single crystals and mesocrystals with dominant $\{101\}$ facets for improved photocatalysis activity and tuned reaction preference. ACS Catal. 2, 1854-1859 (2012).

91 Liu, B. \& Zeng, H. C. Carbon nanotubes supported mesoporous mesocrystals of anatase $\mathrm{TiO}_{2}$. Chem. Mater. 20, 2711-2718 (2008).

92 Yang, X., Qin, J., Li, Y., Zhang, R. \& Tang, H. Graphene-spindle shaped $\mathrm{TiO}_{2}$ mesocrystal composites: facile synthesis and enhanced visible light photocatalytic performance. J. Hazard. Mater. 261, 342-350 (2013).

93 Shevchenko, E. V., Talapin, D. V., Kotov, N. A., O'Brien, S. \& Murray, C. B. Structural diversity in binary nanoparticle superlattices. Nature 439, 55-59 (2006).

94 Urban, J. J., Talapin, D. V., Shevchenko, E. V., Kagan, C. R. \& Murray, C. B. Synergism in binary nanocrystal superlattices leads to enhanced p-type conductivity in selfassembled $\mathrm{PbTe} / \mathrm{Ag}_{2}$ Te thin films. Nat. Mater. 6, 115-121 (2007).

95 Wang, T., Zhuang, J., Lynch, J., Chen, O., Wang, Z., Wang, X., LaMontagne, D., Wu, H., Wang, Z. \& Cao, Y. C. Self-assembled colloidal superparticles from nanorods. Science 338, 358-363 (2012).

(c) (i) () $\ominus$ This work is licensed under a Creative Commons Attribution-NonCommercial-NoDerivs 3.0 Unported License. The images or other third party material in this article are included in the article's Creative Commons license, unless indicated otherwise in the credit line; if the material is not included under the Creative Commons license, users will need to obtain permission from the license holder to reproduce the material. To view a copy of this license, visit http://creativecommons.org/licenses/by-nc-nd/3.0/

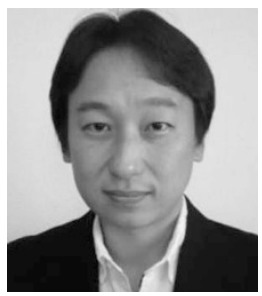

Takashi Tachikawa received his BS and MS in Education from Fukushima University in 1998 and 2000, respectively. He received PhD in Chemistry from Tohoku University in 2003. He worked as a postdoctoral fellow in the Institute of Scientific and Industrial Research (SANKEN), Osaka University, until 2006 and now he is working as an assistant professor.

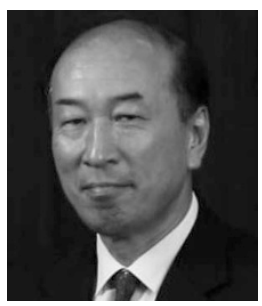

Tetsuro Majima received his BS, MS and PhD in 1975, 1977 and 1980, respectively. He worked as a research associate in the University of Texas at Dallas (1980-1982) and as a scientist in the Institute of Physical and Chemical Research (RIKEN, 1982-1994). In 1994, he became an associate professor in SANKEN, Osaka University. He was promoted to full professor in 1997. 